\title{
Tipología De La Novela Histórica Contemporánea
}

\author{
Hala Abdelsalam Awaad \\ Catedrática de Filología Hispánica, U.Ain Shams, Facultad de Al-Alsun (Egipto)
}

\begin{abstract}
The present study investigates the variability of the historical literary genre with special reference to two contemporary novels: Vázquez Montalbán's Galindez, and Eduar El-Jarrat's The Road of the Vulture. At face value, both works can be considered poles apart: both works are written in two different languages, Spanish and Arabic, belong to two different cultures, and each has undergone a social-historical development inspired by literary theory and a new critical vision. Therefore, both authors are unified by their innovated literary vision: they have created two novels which transcend the frontiers of literary genres following definite principles, and "personal" aesthetics
\end{abstract}

Keywords: Historical novel, El camino del águila, Galíndez, modern story.

\section{Introduction}

La razón del siguiente trabajo puede buscarse en la gran variedad del género histórico cuyo auge, en muchas literaturas, ya viene conformándose desde hace décadas. Aquí, se abordan dos obras, que son fieles exponentes, de al menos dos variantes de la novela histórica actual propiamente dicha: Galíndez ${ }^{1}$ de Manuel Vázquez Montalbán y El camino del águila

${ }^{2}$ de Eduar El-Jaraat.

La presentación y el análisis de estos dos textos me van a permitir ahondar, aunque de modo somero, en la naturaleza y tipología de este subgénero narrativo.

A simple vista, un tipo de trabajo de esta naturaleza plantea más de un escollo. Primero, porque se trata de dos obras escritas en dos lenguas el castellano y el árabe, pertenecientes a dos países diferentes (España y Egipto) que, durante más de un siglo, han tenido, por separado, una evolución histórica, cuando menos, agitada por revoluciones y grandes pasiones.

Sin embargo, no es menos cierto que según la teoría literaria y la visión crítica innovadora, es posible enfocar los textos elegidos desde una perspectiva bastante concreta. Para ello voy a guiarme por criterios reflejados por Celia Prieto en Historia y Novela ${ }^{3}$.

Asimismo, ayuda mucho que ambos escritores fueron coetáneos. Pero, al tiempo que los separan unos años, los une una visión literaria innovadora que tiene su reacción en un sinfín de lecturas y estilos. Por lo cual, es persistente la idea de que escriben un relato moderno, transgresor de géneros, limítrofe de otros subgéneros y conscientemente transmisor de ideas claras, de principios definidos y de determinadas y personalísimas estéticas.

\section{La novela histórica contemporánea:}

Según Celia Prieto la novela histórica, desde las últimas décadas del siglo XX, se distribuye en dos líneas básicas:

a] Una, de corte tradicional, es decir, novela histórica que guarda el respeto a los datos de los acontecimientos historiográficos y el afán de enseñar historia al lector. Pero esta novela lleva a cabo innovaciones tanto temáticas como 
formales que radican en disolver los límites temporales entre el pasado de la historia y el presente de la enunciación; y "la concentración en la subjetivación de la historia"4.

Aquí, el lector no percibe la distancia de los siglos que le separa del narrador porque reconoce en él ideas, actitudes y planteamientos contemporáneos. De las novelas que reflejan más esta tendencia citamos Memorias de Adriano ${ }^{5}$ de Margarite Yourcenar, Extramuros ${ }^{6}$ y Cabrera ${ }^{7}$ de J. Fernández Santos, El bobo ilustrado ${ }^{8}$ de José Antonio Gabriel y Galán, En el último azul ${ }^{10}$ de Carmen Riera, entre otras.

b] Otra, que se denomina nueva novela histórica o novela histórica posmoderna. En este tipo de novela histórica se alteran los rasgos del tipo anterior, y se proyectan las nuevas teorías sobre la Historia, la ficción y la narración. Asimismo, "se altera consciente, voluntaria y manifiestamente las versiones generalmente aceptadas de los hechos, las características de los personajes históricos sus actitudes y motivaciones, el decurso o el resultado de los acontecimientos" 11.

Así pues, la historia admite diversos relatos informativos y comentarios narratoriales que interrumpen la trama. Se forma así un lector implícito que acepte el juego con la acumulación o distorsión de citas, del tiempo y del componente histórico que altera lo narrado.

La distancia entre el presente y el pasado se anula ya que los lectores se mueven a través del tiempo convertido en textos, alusiones o referencias.

Se nota, además, una recuperación del valor de la historiografía pero adquiriendo nuevas tendencias, una historiografía "despojada de sus ínfulas de objetividad y orientada tanto a investigar lo que ocurrió cuanto a detectar y analizar los sistemas de creencias y los criterios interpretativos a través de los cuales las sociedades y los individuos de las distintas épocas construyen su realidad historiográfica”'12.

Así vemos que el interés por saber lo que ocurrió se ha dirigido hacia el quién y el cómo lo contó, también hacia el quién y el cómo lo lee y lo interpreta.

De lo que no cabe dudar es de que la metaficción se constituye en el eje temático y formal de la nueva novela histórica, pues ésta "se muestra como un género metaliterario y metahistórico, que ironiza sobre sus mecanismos de escritura y sobre sus Fuentes" 13 .

Nos encontramos pues con una novela histórica que manifiesta su carácter de comentario, su dimensión metanarrativa e hipertextual, lo que quiere decir, que la nueva novela histórica afronta el problema del anacronismo y se anula la distancia entre los tiempos y por consecuencia "se postula una imagen de la similitud de todos los tiempos en un solo tiempo; el pasado y el futuro habitan el presente"14.

En suma podemos decir, que se trata de dar, al hilo de la narración, una reflexión acerca de la verdad histórica y de las formas de construirlas, amén de contra historias, que se han contado desde otros puntos de vista y de otra manera. Las novelas históricas contemporáneas reescriben las narraciones que funcionaban culturalmente como verdaderas, como históricas.

\section{Galíndez:}

\subsection{Galíndez como novela de tinte innovador:}

En un nuevo cicl ${ }^{15}$ narrativo dentro de su producción novelística, Manuel Vázquez Montalbán escribe una trilogía ${ }^{16}$ sobre la "ética de la resistencia"17, Galindez es la segunda novela de ella.

Lo innovador que aporta Montalbán en esta novela es el de compaginar el nivel de la narración con el de la novela negra norteamericana. 0 sea, el autor intenta ajustar la investigación policíaca que se aplica a crímenes imaginarios de la novela negra con la investigación histórica aplicada a un verdadero crimen del pasado y representarlo por medio de la ficción. De 
tal manera, el hilo conductor del relato aparece en su forma más común de intriga, persecuciones, ambientes de torturas, que están ligados a los hechos históricos y a su interpretación.

Galíndez es una obra realista, que compagina lo novelesco con lo histórico, que el autor lo denomina "revelador» ${ }^{18}$. Es un realismo que implica desvelar aspectos del entorno que permanecían ocultos e iluminar zonas oscuras de una realidad siempre compleja.

Así, Montalbán recupera y rescata del olvido la figura histórica del nacionalista vasco Jesús Galíndez Suárez y reivindica la memoria de este tipo de gente que, según él, son los que han propiciado los cambios históricos; por lo cual se profundiza en la historia española pasada, indagando por los senderos de la memoria histórica y el olvido colectivos, y lo vemos "mediante diversas voces, de varia condición ideológica y moral, complementarias y contradictorias, escruta la historia española pasada y la vida presente, la condición y la ética del exilio y de la resistencia [...”"19.

Pero, ¿por qué fue Galíndez específicamente quien eligió Montalbán para ser protagonista de su novela? ${ }^{20}$. La razón radica en su complejidad jsu manera poco clara! -como lo veremos a continuación- que le convierte en un personaje dialéctico desde el punto de vista histórico, humano y literario.

\subsection{Galíndez: la realidad ${ }^{21}$ y la ficción}

En su testamento ${ }^{22}$ Galíndez apunta:

"Me declaro cristiano y vasco. Como tal, quiero ser enterrado en la fe y en la tierra de mis antepasados cuando esto sea posible. Y ruego a quienes se hagan cargo de mi cuerpo y bienes, que mis restos sean llevados a Amurrio, en la provincia de Álava, Euzkadi, para ser enterrados alli. Quisiera que fuese en la finca de mi padre en Zaraobe, en la parte alta, desde donde se divisan las montañas de mi Patria. A este efecto se reservará la parte de mis bienes que sea necesaria».

Jesús Galíndez era abogado, escritor, nacionalista, demócrata, jurista, humanista, y era ante todo "un complicado ser humano, con sus virtudes, defectos y contradicciones"23. Desde muy joven se interesó en temas relacionados con el País Vasco y en 1932 se ingresa al PNV. Al estallar la Guerra Civil se incorpora al servicio del Comité-Delegación del PNV de Madrid y se convierte en el ayudante del ministro de Justicia, el nacionalista vasco Manuel de Irujo. Así vemos que en Galíndez se encarna "toda una generación de vascos que entre 1936 y 1960 apostaron por lo que ellos creían única vía para conseguir derrocar al régimen dictatorial de Franco. Apostaron por la democracia y la libertad"24.

En 1939 cruza la frontera francesa y viaja hasta la República Dominicana, donde reside hasta 1946.

Desde su llegada a la isla se fundió en la colonia vasca, y al poco tiempo "«movilizaría» a toda la minicolonia del país" 25, y a sus 25 años se convierte en uno de los exiliados más activos de la República. A finales de 1940, asume el mando de la Delegación Vasca, y ésta empezó a colaborar con el Agregado Militar de la Embajada Americana a partir de 1942.

En la isla, Galíndez trabajaba como profesor de historia y literatura en el "Instituto Cristóbal Colón" y en la "Escuela Diplomática y Consular".

Durante su estancia en la República no expresó, de manera alguna su repudio al régimen o comportamiento del dictador Trujillo, pues Galíndez sentía un fuerte agradecimiento a este país que le permitía escapar de Europa, esto lo asegura diciendo: "mientras estuve en el país cumpli lealmente mis cargos técnicos, y no me inmiscuí en política ni para bien ni para mal, (aunque recibi los desahogos personales de las figuras del régimen trujillista en contra del dictador que se ven forzados a adular, no repetiré nombres). Sali del país normalmente en enero de 1946; y sin recato alguno comenté de palabra la situación de la República Dominicana a cuantos querían saberlo" 26.

Con la llegada de 1946, sale de la isla camino a Nueva York, y a los pocos meses de su llegada, rompió su atadura moral con el Gobierno de Trujillo tras un tropiezo con la maquinaria represiva del dictador: "[...] Ese insulto y ruin zarpazo me liberó de todo escrúpulo; y desde entonces me he considerado libre para hablar y escribir en defensa de la libertad dominicana" ${ }^{27}$, por lo cual figura en las "listas negras" del país, y llega a estar bajo el punto de mira de la represión dominicana. Y se convierte Galíndez en uno de los más fuertes luchadores contra las dictaduras. En Nueva York, llega a 
ser representante del gobierno vasco del PNV ante el Departamento de Estado y en la ONU, y cursa la carrera de Filosofía en la Universidad de Columbia.

\section{¿Cómo pensaba Galíndez? ¿Cuál fue su ideología?}

La primordial meta de Galíndez era volver a Euskadi, a un Euskadi demócrata, viene después la defensa de los derechos humanos. Además, era un anticomunista, pero opuesto al anticomunismo norteamericano y distinto al franquista y al dominicano, que se practicaba por parte del régimen trujillista y que, según él, sólo servía para el desarrollo del comunismo.

Durante casi doce años, colaboraba Galíndez con el FBI con el sobrenombre de «Rojas» y el código en clave «NY507».

A partir de 1954 empezó a escribir su tesis doctoral sobre Trujillo: La era de Trujillo (Un estudio casuístico de dictadura hispanoamericana), y más aún, como no había podido dar rienda suelta a todo su odio por el dictador en la tesis, decidió escribir una novela cuyo título El carnicero del Caribe.

Muchos han recomendado a Jesús, incluso el FBI, que dejara de escribir la tesis sobre Trujillo. Pero el Delegado, por lo menos al principio, no creía que su libro le provocaría la muerte y seguía su trabajo por que "contaba con una baza a su favor. Sabía que era una persona muy conocida en Nueva York y profesor de una de las universidades más prestigiosas del mundo, y era, en teoría, prácticamente imposible que Trujillo intentara atentar contra él'28. Trujillo, por su parte, amenazaba con matarlo, y desde entonces andaba Galíndez con muchísimo cuidado.

El 21 de noviembre de 1955 presentó Galíndez su tesis doctoral en la Universidad de Columbia. El 12 de marzo de 1956 fue secuestrado en plena Quinta Avenida de Nueva York y conducido a la República Dominicana, donde, tras ser sometido a tortura, fue asesinado. De su cadáver no quedó rastro. Y la Universidad de Columbia, por su parte, le concedió el título de doctor honoris causa post mortem.

Sobre esta base histórico-documental construyó M. Vázquez Montalbán su novela.

Hay que señalar, desde un principio, que el relato de Montalbán no consiste en componer una biografía, ni una novela histórica convencional, ni tampoco de espionaje -aunque tenga rasgos de cada una de ellas- sino en hacer una novela crónica en la que se mezclan la realidad y la ficción, los personajes reales e inventados y esto lo indica diciendo: "He tratado de buscar lo que llamaría el efecto Zelig, como en la película de Woody Allen, es decir, alcanzar un nivel en el que lo real pueda parecer ficción y la ficción parecer real" 29 con el fin -como se ha dicho- de escudriñar la historia española pasada y la vida presente. "Frente a la crisis de los saberes del s. XX, Galíndez trata el dramático declinar de las ideologías con un discurso no argumentativo que reemplaza artísticamente los conceptos por las imágenes"30.

En consecuencia afirmamos que esta historia es subjetiva, lo que quiere decir, se privilegian ciertos hechos y se ocultan otros, además la cuestión de la Guerra Civil y la lucha por un País Vasco autónomo se limita solamente como un mero trasfondo.

Y, como surge Galíndez de la combinación de la Historia con la novela, el papel de protagonista lo tiene Muriel Colbert, el ejemplo de Galíndez, y no él. En la novela se cuentan los avatares, las intercepciones y presiones que sufre esta investigadora norteamericana, becada y mormona renegada, que 30 años después de la desaparición de Galíndez en Nueva York, prepara una tesis doctoral sobre: La ética de la resistencia: el caso Galíndez.

Muriel emprendió su trabajo recorriendo todos los lugares donde estuvo Galíndez. Durante este recorrido, que empezó de una forma estrictamente académica y acabó convirtiendo en vital y la llevó a la expiación y a la muerte, se enfrentó a muchos problemas y obstáculos; amén de caer bajo fuertes presiones: primero, de parte de Norman, su director de tesis, cuando quiso reorientar su trabajo, luego de don Angelito -por encargo de la CIA- tratando de convencerla de abandonar su investigación.

La figura de Galíndez le atrajo la atención y su apariencia contradictoria le ha entusiasmado para su trabajo. Así que, en busca de una identidad más de acuerdo con su ideología, y para lograr la dignificación personal, ella, en su entusiasmado rastreo, busca "todos los Galíndez posibles" (p.47) $)^{31}$, pero se decide por un sólo Galíndez, aquel que fue asesinado en defensa de sus ideales. De tal modo intenta Muriel recuperar su biografía y reivindicar su memoria: 
«Muriel se había tomado el caso Galíndez como una cuestión personal» (p.47).

Esta toma de postura suya es la que devuelve a este hombre, Galíndez, su dimensión individual, o sea, lo vuelve a escala humana y no a un mero personaje símbolo de libertad, de justicia y lucha contra la dictadura:

"La trama, entendida como res gestae y como historia rerum gestarum se repite, o mejor dicho, se refleja"32. Lo que quiere decir, que ambas historias -verdadera y ficticia- están fundidas la una en la otra, borrando rasgos característicos del original y de la copia, y, de una manera llamativa, se nota la similitud entre las existencias de Muriel y Galíndez y las frecuentes coincidencias entre las biografías de ambos: la desaparición de los dos en Santo Domingo, él por haber escrito una tesis sobre el dictador Trujillo, ella por preparar una tesis sobre Galíndez.

Huelga aqui afirmar que, a lo largo de la novela en todas las partes protagonizadas por Galíndez o Muriel se entremezclan las palabras del primero y los pensamientos de la segunda. Según, Pitarello se atribuye esto a la representación del desdoblamiento autobiográfico. He aquí el comienzo de la obra donde los versos del vasco se mezclan con los pensamientos de la investigadora:

«En la colina me espera...en la colina me espera...» El verso te da vueltas por la cabeza, como si fuera un surco rayado de un Viejo disco de piedra. "En la colina me espera...en la colina me espera...» "Y volveré... volveré o me llevarán ya muerto... a refundirme en la tierra...» Ni siquiera eso fue posible, Jesús, musitas y te parece hablar con ese extraño compañero enquistado que desde hace años llevas dentro de ti. El viento limpia el valle de Amurrio y te levanta las faldas sobre esta colina de Larrabeode, la colina escogida como si fuera la colina, exactamente, la colina que esperaba a Jesús de Galíndez. Tienes frío y los huesos aguados por el viento que pule el pequeño monumento funerario dedicado a Jesús de Galíndez y por la humedad retenida en el depósito que se cierne sobre el valle con su amenaza, promesa de agua. La estela de piedra parece ridícula y amedrentada por el colosalismo del depósito, poco más que un pretexto para no perder del todo la memoria, una memoria, un homenaje residual y probablemente incómodo (p.9)».

Muriel, amén de su apasionado rastreo, no tiene la intención de descubrir toda la verdad, ni de encontrar a los asesinos, sino quiere llegar a entender el "dilema moral en la encrucijada histórica" ${ }^{33}$ en la que se encontraba Jesús de Galíndez, esto lo que ella advierte desde un principio:

"Galíndez era un nacionalista vasco... Pero eso no me interesa. No quiero saber toda la verdad sobre el caso Galíndez, sólo quiero saber una verdad [...] Quiero saber... Tal vez, por qué se la jugó (p.24)».

Y por ello intenta ocupar los espacios habitados por él y a revivir «la atmósfera que rodeó a Galíndez en sus últimos momentos» (p.294).

Al final, Muriel pudo traspasar a su propia vida el sentido de la ética de la resistencia que buscaba en la memoria reivindicada de Galíndez. Además, encontró al «hombre entero» (p.328), el hombre de su vida aunque sea "profeta impuro» (p.317), pero esta impureza es lo que le humaniza. Y se convierte Galíndez, para ella, en un modelo a seguir y que en su tierra encontró el sentido de su existencia. De este modo, afirmamos lo que dijo $\mathrm{C}$. Bértolo ${ }^{34}$ de que lo que une los destinos de ambos personajes es la misma resistencia ética a no resignarse, a no perder ni, sobre todo, perderse en tiempos de derrota.

A lo largo de la novela van apareciendo recortes del cuerpo historiográfico del caso Galíndez. El motivo por el cual se exhibe esta cadena intertextual es la revelación de las perspectivas subjetivas de las presuntas verdades.

De estas llamadas intertextuales nos encontramos con memorias personales, entrevistas, cartas, tratados, refutaciones, informes como el informe oficial de Porter y su opuesto de Morris Ernst (Report and Opinion in the matter of Galindez) «Todo lo que Porter había puesto en Blanco, Ernst lo puso en Negro» (p.108), documentos como el propio libro de Galíndez, su tesis, el de Manuel de Dios Unanué, y también libros en los que se inscriben historias contrarias que figuran el caso Galíndez como el de Antonio Bonet ${ }^{35}$. 
Toda la novela está basada sobre el juego de la doblez, y Montalbán nos presenta diversos personajes destruidos, llenos de dobleces, que «a menudo nunca fueron lo que aparentan ser» (p.344).

El núcleo central de la obra está formado en torno a la doblez moral de Jesús de Galíndez. Tras su muerte empezó a revelarse su condición de doble agente, Galíndez era un activista del PNV y también trabajó de manera cubierta para el FBI y CIA; pero este doble papel suyo estaba justificado por su compromiso con la causa vasca y por la recuperación de la libertad de su País Vasco. Otra vez aflora las diversas facetas del enigmático personaje de Galíndez.

Muriel en su doble papel maternal/investigador ${ }^{36}$ intenta comprender la toma de postura de Galíndez, sin acusar ni justificar su doble papel, "...daba risa la condición de doblez en la que todos vivíais mientras hacíais proclamas públicas de unicidad y entereza hasta la muerte. [...] Tú proclamabas que el fin no justifica los medios, pero sabías que te mentías» (p.59).

En el transcurso de la trama emana la doble actuación de los agentes secretos de la historia. Tal es el caso de Martínez Jara, alias el cojo, el emisario de Trujillo «que había sido agente doble de todos desde la Guerra de España agente de Franco y de la República, matón en México, conspirador a favor y en contra de Trujillo» (p.59).

Asimismo, la novela desarrolla el doble juego del gobierno norteamericano hacia España tras la Guerra Civil.

En cuanto al caso Galíndez, la propia organización de los servicios secretos norteamericanos «jugaba un doble juego, muy típico de los yanquis. Mientras una parte luchaba por investigar la verdad de lo sucedido, otra parte trabajaba para borrar las pocas pruebas que quedaban» (p.293).

Por debajo de la historia que se narra emana la injusticia y las opresiones de las dictaduras en Hispanoamérica, opresiones sádicas y crueles. La obra denuncia tales brutalidades y opresión histórica, mediante la presentación de escenas de torturas chocantes, dolientes, pero a la vez muy fieles.

Aparece, asimismo, en el relato el submundo de la emigración hispana en Miami y Nueva York.

Hay aquí que anotar que, en el transcurso de la novela deducimos que Muriel es el disfraz que adopta Montalbán con el fin de darnos su visión de los hechos.

Montalbán, en su constante preocupación por recuperar la memoria histórica y su deseo de indagar en la historia y de seguir haciendo preguntas sobre el pasado y el presente, se pregunta en boca de Muriel: « ¿Acaso el olvido de Galíndez no es consecuencia de esa voluntad de ahistoricismo que lo invade todo, que quiere liberarse de la sanción moral de lo histórico?» (p.77). Así como, la devolución de Muriel al delegado de su dimensión individual y la postura que ella adopta hacia él, refleja la mirada que toma el escritor hacia este personaje: un profundo respeto humano.

\subsection{Las técnicas narrativas:}

La técnica constructiva de esta novela híbrida, donde se mezcla la historia y la memoria, lo culto y lo popular, está basada en la técnica del collage. Nos encontramos con documentos, recortes de periódicos, extractos de libros, diálogos, sin alcanzar, siempre, a determinar la frontera entre lo real y lo ficticio, lo que significa dar cabida a "una multiplicidad de voces recuperadas del olvido, de ahi el carácter de mosaico de textos fragmentados o de narración polifónica"37.

En cuanto a la focalización, no se adscribe la novela a una visión unitaria, particular de la historia, sino que la focalización consiste en un contrapunto entre tres enfoques narrativos de sus tres protagonistas. El primero, es la historia de Galíndez que se cuenta, la última vez que fue visto en Nueva York, su desaparición, su secuestro, tortura y al final su asesinato. El segundo, se trata de Muriel Colbert y su investigación sobre el caso, recorriendo todos los lugares donde estuvo él. El último, es el enfoque que concierne a Robards, el agente de la CIA que interviene en el trabajo de Colbert. Una intervención que lleva al asesinato de ésta. 
Presentar la focalización con la intensificación de la credibilidad y aumentar la sensación de opresión, tiene como objetivo provocar una concienciación en el lector que va en paralelo con la de Galíndez y Muriel.

En cuanto a la técnica de construcción de la narración veo que es singular. Me refiero aquí al punto de vista.

Galíndez es una novela descentrada con múltiples puntos de vista, por lo cual la obra oscila entre dos formas pronominales. La vivencia auténtica y fabulosa se funden, entonces a Muriel y Galíndez les concierne la misma perspectiva, el mismo punto de vista. Pero Montalbán no recurre a la primera persona cuando habla la protagonista o el delegado, sino a la segunda persona ${ }^{38}$, lo cual quiere decir que el tú (sea de ella o de él) supone un yo locutor sin identidad fija. Los tiempos verbales, en este caso, están en presente y abundan los monólogos interiores.

La elección de Montalbán de la segunda persona para su narrador, implica que este escritor crea un relato inhabitual en el que no finge la voz de las víctimas, ni tampoco cuenta desde fuera y, además, renuncia a las convenciones de verosimilitud, típicas del género de la novela histórica tradicional.

En cuanto a la tipología del narrador, es un narrador omnisciente, pues sabe todo lo que piensan e imaginan los demás personajes, y abarca todas las situaciones posibles.

Esta fusión de la segunda persona y de la omnisciencia origina un continuo vaivén entra la voz de Galíndez y la de Muriel, o sea, entre quien es narrado y quien narra, el ejemplo más representativo es la escena de tortura que sufre Muriel llegando a un momento en que se diluye la voz de los dos, sin poder distinguir si la tortura la está sufriendo ella o él.

Cuando en el discurso no se trata ni de Muriel ni de Galíndez, aparece la tercera persona derribando el muro entre ficción y realidad y "descargando la tensión creada por el tú y calienta la introspección de Muriel y Galíndez" ${ }^{39}$. Los tiempos verbales, en este caso, están en pasado, y las descripciones de las situaciones están detalladas y se produce un vaivén entre los discursos directos e indirectos.

En esta novela, la complejidad de la galería de personajes-desintegrados, que no son lo que aparentan ni de una pieza, no está trazada al azar ni es un puro divertimiento y podría según Michel Santiago ${ }^{40}$, revelar una teoría del comportamiento.

Muriel es el personaje positivo de la obra, que no encuentra entre los vivos un modelo a seguir, tampoco encuentra entre ellos una vía para manifestar su oposición frente al sistema. Para Robards y don Angelito ella es una de los «pobres inocentes» de "Los santos laicos» (p.265). Ella encarna, según Montalbán, la conclusión de la novela: "Cada generación hace frente a sus desafíos y aún queda una raza de inocentes dispuestos a asumir riesgos éticos".

Robards, «el hombre cúbico» (p.51), el agente de la CIA, y don Angelito, el sicario, son dos ramas del árbol de la derrota. El primero, amante de la poesía y buen lector de T.S. Eliot, para él no cuentan los sentidos, prefiere controlar la realidad. Robards se nos presenta como un individuo dotado de vida propia.

Don Angelito, que se define como "ciudadano del mundo y libre pensador" (p.137), es el personaje brillantemente diseñado y uno de los mejores logros de la novela pues, a diferencia de Robards, ejerce desde los sentidos. Es el verdugo que se convierte en víctima. Angelito -llamado también Voltaire- representa el arte del engaño que está en condición de interpretar en cada situación su papel adecuado: "Construirse en trampa mortal es la jerarquía superior de su juego vital" 41.

Por otra parte, nos encontramos con Radcliffe, el profesor de ética que dirige el trabajo de Muriel. Es un personaje en conflicto, un cobarde que vende su conciencia por su bienestar, es, además, «una asquerosa basura» (p.51) «un radical de boquilla que quiere conservar la radicalidad y el nivel de vida» (p.109) como lo califica Robards.

Ricardo, el amor de Muriel en Madrid, es el personaje dinámico por excelencia. Al principio se presentaba como un ser inoperante, con tendencia a la normalización, al espejismo occidental, "una especie de Limbo lúdico posible gracias a la ausencia de compromiso con la realidad ${ }^{42}$, pero cuando su amor advierte la injusticia se cambia totalmente y es capaz de 
romper con todo y, emprendiendo la investigación de la desaparición de Muriel, renueva el ciclo elaborado por Galíndez y Muriel, llegando a ser el siguiente eslabón de la cadena Galíndez.

En lo que concierne al desarrollo del tiempo, diremos que es una narrativa descentrada. La fragmentación espaciotemporal adopta una estructura quebrada que ordena la acción al revés de su cronología histórica, así que se inicia la acción en 1986, con el trabajo de Muriel, se vuelve treinta años atrás, hacia 1956 la última vez que se vio Galíndez en Nueva York, y se retrocede una vez más hasta 1946 cuando estuvo éste en Santo Domingo. Debido a esto, abundan los saltos retrospectivos que frustran la linealidad temporal, predomina, asimismo, el flash-back. Los monólogos interiores, el estilo indirecto libre abundan en el contrapunto entre el agente del CIA, Muriel y Galíndez.

En el mismo plano, los paisajes no son un mero telón de fondo, sino juegan un papel importante intercambiando con los personajes y participando en su construcción cumpliendo lo que se ha dicho, que la persona es producto de su relación con el mundo, a condición de que tal persona sea responsable de sus propios actos.

Llama la atención los lugares y paisajes detenidamente detallados y que son producto del recorrido del propio autor por todos los lugares recorridos por el propio Galíndez: "Me he detenido ante la casa en que vivía en la calle Lovatón [...] También he paseado por el parque donde se reunía con su contacto de la embajada americana ${ }^{43}$.

En cuanto al lenguaje es adecuado, ceñido, que oscila entre lo culto y lo popular.

Se nota en la novela el uso de las palabras extranjeras, los dialectos latinoamericanos, los versos vascos que están al servicio de la trama. Hay en la obra una mezcla de tonos: desde el más duro, manifestado durante las torturas, al más tierno, representado en la conversación de don Angelito con sus gatos y en las escenas familiares del País Vasco. Montalbán utiliza los procedimientos del periodismo de investigación para construir su ficción.

\section{Es imprescindible prestar atención al paratexto.}

El título juega un papel muy importante en la definición del tipo de la obra, y, por consiguiente, en la creación del lector implícito. Así, lo ve Charles Grivel: "El título manifiesta la naturaleza del texto y por consiguiente el género de lectura que le conviene" ${ }^{44}$. Por lo cual Galíndez, desde un principio nos hace pensar que estamos ante una novela histórica.

Ahora bien, como estamos ante una nueva tipología de novela histórica, los prólogos y epílogos, cuya función era informar al lector de las fuentes historiográficas utilizadas para la elaboración de la obra y que aparecían en ella, ya su función metanarrativa se desplaza al interior de la trama, asumida por el narrador o los personajes. Pensamos, por ejemplo, en las cartas, informes, extractos de libros, etc.

En cuanto al epígrafe, la novela empieza con una dedicatoria a la señora Rosa, la madre del escritor, que falleció unos meses antes de la publicación de la novela.

En seguida, encontramos una cita interpolada: La palabra encadenada de Joaquín Balaguer, secretario de Trujillo y posteriormente presidente de la república, "esquizofrénico ejercicio de reescritura de su propio pasado, en forma de autoconfesión y descargo de conciencia" ${ }^{45}$. Es como una especie de resumen de la obra.

Por debajo de la primera cita, Montalbán eligió unos versos muy representativos de Charles Baudelaire que describen un estado de desesperación.

Al final del libro el autor hace referencia geográfica "Villa Analisa", a la casa de quien él considera uno de sus mejores amigos, el cantante Raimon.

Antes de terminar hay que aclarar que el trabajo no tiende a decantarse a la visión pesimista de Pittarello acerca del "amargo final de la obra que no deja lugar a la esperanza"46, porque se plantea cierta esperanza encarnada en el personaje de Ricardo, exponiendo la repetida lucha contra el silencio que envuelve a los crímenes políticos y que, tarde o temprano, tendrá resultados menos tristes. 
Concluyo aclarando que Galíndez pertenece a la nueva tipología de la novela histórica postmoderna, lo prueba la fragmentación de lo histórico, como la de la narrativa que es característica de la condición posmoderna.

Galíndez atrae la atención de los tranquilos lectores para que tomen postura hacia los mecanismos sociales. Y ahí reside el papel del lector, su tarea, para codificar el doble relato de la historia a la manera de la parábola cinematográfica de Rashomon:

"En la película se cuenta un mismo hecho mediante distintas apreciaciones de diferentes testigos y el espectador ha de hacer el esfuerzo de elegir una de las versiones o ir reuniendo elementos de una y de otra» (p.89).

Por lo cual, se puede decir que la palabra la tiene el lector, el lector cómplice, investigador e intérprete característico de la novela histórica posmoderna.

\section{El camino del águila (Tarīq al-nisr):}

\section{Introducción:}

Si en Galíndez, intenta Vázquez Montalbán conciliar el nivel de su narración con el de la novela negra, en El camino del águila, Eduar El-Jarrat compagina su trama con la novela autobiográfica, pues la obra reivindica personajes y lugares reales, amén de inspirar acontecimientos vividos por el propio autor, algo que aclara El-Jarrat diciendo: "Desde los albores de mi juventud participé activamente en los actos políticos, en la política revolucionaria antimonárquica, a la que me entregué completamente $y$, al final, fui detenido por dos años o un poquito menos durante el reinado del rey Farouk en los campos de concentración de Abu-Kir en Alejandría, El Huckstep en el desierto cairota y en El-Toor en el desierto del Sinai" 47.

Pero, con una lectura atenta, nos enteraremos de que el relato está fuera del ámbito autobiográfico, ya que el autor no se limita a retratar minuciosamente a sus compañeros o a reivindicar lo ocurrido, sino que abre un gran espacio al sueño y a las meditaciones, por lo cual, la trama narrativa se interrumpe constantemente con reflexiones y comentarios del autor sobre la mayor o menor fiabilidad de los testimonios que recoge, y sobre la inevitable ficcionalidad que implican la escritura y la narración. En lo que concierne a este punto dice El-Jarrat: "No es una autobiografía, porque a pesar de que conlleva hechos reales, tiene, al mismo tiempo, acontecimientos completamente imaginarios. En ella, además, se ha alternado los papeles de algunos personajes, o se ha reivindicado la memoria de otros. Lo mismo ocurre en cuanto a los acontecimientos: se trata de jugar con la realidad y no obedecerse a ella" 48.

El camino del águila es una novela crónica, de pocos acontecimientos, cuyo soporte temático es el pensamiento, planteamientos y aplicaciones del socialismo en Egipto. Es una especie de registro y documentación de los debates y discusiones ideológicos y el estilo de trabajo de cada círculo. Pero el autor da importancia, sobre todo, a las razones por las cuales los personajes eligen la revolución como camino a seguir en la vida.

La obra, en el hilo de su trama artística y narrativa, lanza una serie de preguntas - acerca del destino de la patria, del valor de los actos revolucionarios y del martirio; así como bucea en la infraestructura del movimiento revolucionario en Alejandría, representando el estallido de las manifestaciones, la formación de las organizaciones y los círculos revolucionarios clandestinos y oficiales. Asimismo, presenta las luchas de las ideologías en Egipto a finales de los años cuarenta, amén de analizar las contradicciones de las corrientes políticas de aquellos años:

«Sabía que iban a llegar. Llegarán esta noche sin lugar a duda. Pero, ¿qué puedo hacer?» (p.7) ${ }^{49}$.

Así empieza la novela con la espera del protagonista de la llegada de los agentes de la policía secreta para llevarlo a un destino desconocido, es decir, se inicia con el acontecimiento primordial en el pensamiento del narrador: su detención. La detención que duró veinte meses, la noche del 15 de mayo de 1948 -fecha crucial pues coincide con la primera Guerra de Palestina- hasta febrero de 1950, es la experiencia que representa el eje en el cual El-Jarrat teje la trama de su obra: 
«En esta noche, el 15 de mayo 1948 me arrestó el gobierno de El Noukrashi, la noche de la primera Guerra de Palestina, con cientos de personas de toda clase: " "peligrosos» o "sospechosos» políticos, de los más derechistas a los más izquierdista ...» (p.238) ${ }^{50}$.

Luego empieza Youssef, narrador-protagonista, a revelar la sucesión de acontecimientos y en un salto retrospectivo técnica muy frecuente que trataremos más adelante- cuenta la formación de su célula revolucionaria, y cómo se formó en su inicio con unos cuatro o cinco amigos, pero poco a poco se le iba juntando otra gente de diversas clases y cargos hasta que «el número de los miembros de nuestra célula y sus camaradas y quienes simpatizaban con él no sobrepasó las 40 ó 50 personas» (p. 204) ${ }^{51}$.

En este círculo revolucionario, se distribuía el trabajo por grupos entre los miembros, pero, al final, todos obedecían al mismo plan. Nos explica el narrador, también, que se adoptaron dos corrientes entre los miembros: una hacia el anarquismo y, otra, la del compromiso con el texto marxista trotskista. Pero, pese a estas contrariedades, fue una Célula muy bien organizada y que gozaba de buena reputación y posición en los ambientes universitarios y colegiales.

Asimismo, nos informa de las huelgas de los estudiantes universitarios, de las manifestaciones contra el rey y los ingleses, de las conversaciones y charlas que circulaban entre los miembros de la Célula, sobre La Primera Internacional y sobre la dogma de Marx y la anarquía de Bakunin.

Charlas acerca de Trotski y su rival Gorki, sobre la intención de una adaptación entre el socialismo y la psicología de Freud. Discusiones entre quienes piden quemar etapas y quienes piden el compromiso de la graduación en cuanto a la vocación de la República Comunista:

"Me distraía recordando mi discusión candente de ayer con "Fatouh El Khafas" acerca de la lucha en La Primera Internacional entre Marx, con su autoridad, aplicación y su fe en la prioridad de sus sugerencias, y Bakunin, el liberal de mente abierta hacia las posibilidades y su inocente fe acerca de la eliminación del Estado, pues es un mal cualquier que sea este Estado, su constitución o su punto de partida... » (p.37) ${ }^{52}$.

También presenta continuos debates sobre cuestiones políticas, sociales y psicológicas.

En este mar de debates, el narrador menciona a diversos líderes, filósofos y profesores: Trostki, Bakunin, Freud, Hegel, Kropotkin, Ramsis Younan, Salama Mussa, entre otros. Hace referencia, además, a una copiosa lista de libros: El anarquismo, La guía de la mujer inteligente hacia el socialismo de George B. Shaw, La Cuarta Internacional, entre otros.

El 15 de mayo detienen a Youssef y lo llevan a la prisión de "Karmouz" donde lee El dragón dorado, antología de la poesía inglesa. Al llegar al campo de concentración de "Abu Kir", continúa, sigilosamente y con mucho cuidado, su actividad política con sus compañeros. Ahí, juntos, publican un periódico mural, traduce la obra teatral Los bajos fondos de Gorki que se estrena por los prisioneros; también aprende el francés y trata de aprender el alemán y el ruso. En las cartas a sus familiares pide libros, como las traducciones inglesas de Apuntes del subsuelo y Recuerdos de la casa de los muertos de Dostovievsky, La tierra virgen de Turgenev, La evolución creadora de Bergson y otros.

Al trasladarse al campo de concentración de "Al Toor", se encuentra con un conjunto variado de hombres -de los más derechistas a lo más izquierdistas y los del medio-. Personas que representan la nobleza, el coraje y la paciencia, otras la deslealtad, la hipocresía y la cobardía.

En medio de todo esto y en el transcurso de la novela, el protagonista no deja de hacer todo tipo de preguntas, hasta poder decir que la novela es un conjunto de interrogaciones. Éstas no están a un solo nivel, sino que están, como lo denomina Maher Shafik ${ }^{53}$, a nivel del microcosmos y del macrocosmos.

Al nivel del microcosmos de la novela, o sea su pequeño mundo, nos preguntamos: ¿llegarían o no los agentes de la policía secreta en esta noche para llevar al narrador?, ¿Acaso hay un sentido metafísico en este acto revolucionario en el cual se incorpora?, ¿Sería "Helmy El Raiss", su amigo, quien denunció a sus compañeros al Servicio de Inteligencia?, 
siendo el único que estaba enterado del lugar y de la hora de la cita. Además se preguntaba si acaso había desaparecido el anhelo de justicia y se la libertad, la música juvenil llena de esperanza y fuerza?, y muchas otras.

En cuanto al macrocosmos, su mundo más grande, tenemos preguntas como: ¿desde cuándo era la lógica el criterio en la revolución o en el arte? ¿cuál es la relación entre lo relativo y lo absoluto, y entre sueño y realidad?, ¿acaso los fines justifican los medios?.

Suscita la novela, también, preguntas acerca de la lealtad y la tradición y responde el protagonista: "No encontré ninguna respuesta: ¿acaso nunca he encontrado respuesta a ninguna pregunta?" (p.334) ${ }^{54}$.

Todo eso nos hace saber de que estamos ante un narrador intelectual, izquierdista y revolucionario, afiliado al "pequeño y pobre círculo revolucionario, tan pobre hasta la nada" (p.7 7$)^{55}$.

Estamos ante un joven al que le interesa tanto la literatura como la filosofía, que ha participado en los actos revolucionarios "no solamente bajo el emblema del socialismo o el anticolonialismo y la explotación, sino que insiste en que la libertad sea la del individuo y de la sociedad, y que éstas van íntimamente emparejadas con la justicia" (p.13) ${ }^{56}$. Es, además, un crítico, funcionario, escritor, traductor, hombre de debate, comprometido con las doctrinas socialista y marxista, pero al mismo tiempo las critica. Es un egipcio, copto y ortodoxo, en quien arde la llama de la revolución como las del cuerpo. Todo esto se nos revela, como hemos dicho, a la manera de la autobiografía, pero una biografía de la sociedad y de la masa al mismo tiempo.

\subsection{La identidad del texto:}

Como ya hemos dicho, a pesar de que en los pliegues de El camino del águila hay muchos rasgos que muestran que esta obra se inspira en acontecimientos vividos por el autor, sin embargo la obra se aleja de la autobiografía, puesto que el texto se apoya en la ficción y la imaginación. Dar a la imaginación un lugar primordial, es una de las estrategias de Eduar El-Jarrat.

En esta novela, lo que mueve al autor es tratar a la par el componente histórico y ficcional, fundir el uno en el otro por medio de vestir lo histórico con ropaje ficticio, y viceversa.

Conviene aquí hacer hincapié en el tratamiento del componente histórico/ficticio, pues el tratamiento del autor está al compás de las tendencias de la nueva novela histórica, 0 sea, con la metaficción historiográfica ${ }^{51}$, donde se borra la frontera entre lo real y lo ficticio, lo certero y lo novelesco.

El narrador-autor, por su parte, afirma que muchas veces recurre a la imaginación, a la invención o a la ficción:

"Claro que puedo inventar las razones y falsificar las circunstancias -todas y de una manera muy convincente- como hago a veces dentro de este texto cambiante lleno de los sucesos a medias y los semi recuerdos, amontonado con hechos reales y vuelos de la imaginación. Sin embargo no lo haré, por lo menos ahora...» (p.195) ${ }^{58}$.

Estamos ante un relato que trata de captar un yo metamórfico, variante. El escritor, después de más de cincuenta años, intenta reivindicar sucesos que formaron un punto crucial en su vida,

sin embargo, no los relata ordenadamente en una linealidad ascendente, sino que abre el camino a la imaginación, tomándose a sí mismo como el foco para reivindicar estas relaciones y moldearlas en palabras y diálogos que puedan llegar a ser muy parecidos a lo que realmente sucedió, mas es a través de su memoria que disponemos de las voces de los demás personajes.

Así pues, esta escritura no se ocupa de coincidir con un suceso histórico o con una referencia exterior, sino que pretende iluminar aspectos del yo múltiple con sus incesantes e inestables preguntas acerca del destino y de la existencia, de su relación con el otro, con la sociedad y con la Historia; la búsqueda de respuestas a tales preguntas pasa a través de la 
autoficción que entremezcla las cartas y los espacios, como, también, elimina el abismo que separa la conciencia intelectual, lógica y la absorción de la intuición y el desvelamiento poético.

En consecuencia, decimos que estamos ante una novela autoreflexiva y autoficcional donde la diégesis está ligada al yo y a su laberinto.

\subsection{La estructuta del texto:}

En lo que atañe a la estructura de El camino del águila hay que aludir a que esta novela dista del modelo de la novela clásica que asciende gradualmente de un ayer, a un hoy y a un mañana, de un suceso a otro que le sigue o de una novela con principio, medio y fin.

En la novela, los sucesos, las fechas, los tiempos y los espacios se funden con la fantasía y la imaginación. No obstante, esta mezcla no altera la estructura narrativa, al contrario la libera y la refuerza. La obra, además, no la envuelve un sólo género expresivo, sino que lo que dice este texto nos llega a través de múltiples vías con elementos formales comunicados. Esto lo afirma El-Jarrat diciendo: "Era un aventurero y sigo siéndolo. Un aventurero que sobrepasa las técnicas, los límites y los géneros literarios hasta llegar a la amplitud del texto con su estética ilimitada, alejándome de los moldes acuñados"59.

En consecuencia, decimos que El-Jarrat, en su constante esfuerzo para alejarse de las técnicas de la narración tradicional, recurre a la transgresión literaria por medio de artículos, entrevistas, resúmenes de libros, etc., con los que se amontona la novela.

\subsection{Las técnicas narrativas:}

\subsubsection{El punto de vista:}

La novela es una sucesión de imágenes narradas desde la conciencia del narrador. Está narrada en primera persona, el protagonista es un Yo testigo. Este protagonista está lejos del estereotipo, como lo explica Abdel Fatah Rizk 60: "la maestría del autor radica en el juega con las reacciones, hasta formar una visión íntegra del tratamiento con los personajes, suceso tras otro".

Es, además, selectiva y omnisciente. Selectiva porque el autor selecciona a determinadas personas para informarnos de los hechos; y omnisciente porque nos encontramos con más de un punto de vista.

La primera voz que hayamos es la del narrador. Ésta está envuelta con la imaginación, la fantasía y la autoficción, mientras que la otra, la del autor, asegura una vivencia, una realidad sin considerar lo que dice como una violación a las normas de la novela:

"Vuelvo pronto al hilo de la narración que parece ser natural y habitual - a pesar de que no me gusta y seguiré violando siempre su supuesto territorio sagrado-. Sí, es mi pura y propia voz, que no está confundida con la del narrador que combina su imaginación, su realidad y sus fantasías con la dureza de los recuerdos: Él tiene todo el derecho a ello, como imagino que yo también tengo todo el derecho de hablar con mi propia e inconfundida voz» (p.84) ${ }^{61}$.

Hay que señalar la afinidad entre Galíndez y esta obra en cuanto a la intervención del autor en el texto.

En ésta, este fenómeno ocurre cuando se hace referencia a los verdaderos luchadores, intelectuales o compañeros, también cuando hay documentación o registro histórico o historiográfico.

En Galíndez sucede lo mismo, el autor se introduce en el relato cuando quiere opinar acerca de algo, salvo una sola diferencia, que en esta obra se introduce el escritor por medio de la voz de Muriel como disfraz del propio Montalbán.

\subsubsection{Tiempo:}

Abordando la técnica del tiempo en esta obra, notamos que está elaborado no de un modo somero, sino con maestría y dominio. 
El camino del águila, al igual que Galíndez, lejos de ser una narrativa ordenada, es una narrativa con grandes saltos de tiempo y lagunas que frustran su linealidad; así como, la fragmentación espacio-tiempo que adopta una estructura quebrada ordenando la acción al revés de su cronología histórica.

El tiempo exterior o del relato, está limitado a poco menos de dos años, sin embargo, la obra en su totalidad es un cuadro panorámico político, psicológico y social que abarca decenas de años de la vida del protagonista y de los demás personajes.

La novela, asimismo, bucea en épocas más remotas de la historia de la patria, en los tiempos de glorias y derrotas.

Y como hemos dicho que la novela se apoya en la ficción e imaginación, entonces estamos en el tiempo de Youssef, el narrador, que considera que la «revolución - sea en política o en el arte- es irrupción y violación y no adaptación a las circunstancias» $($ p.101) 62 .

Es el tiempo del narrador que lee libros en todas partes, libros sobre los revolucionarios y los anarquistas: Libros de Maximov, de Freud, de Tolstoi, Marx, Hugo, Baudelaire o de T.S. Eliot.

Del hombre que trata de buscar un equilibrio entre el yo, el otro y el yo supremo. Del narrador que según dice "entiendo concientemente que mi odio a la violación individual -con lo que lleva de brutalidad- se debe a mi herencia copta, lo escondo detrás de una nueva fe en la violencia popular colectiva que es la única justificada, inocente y determinante para enfrentarse a la violencia del Estado Capitalista y a la ocupación "(p.33)63.

Y por ser, también, la novela de las verdades, la historia y la historiografía, estamos, pues, ante el tiempo del autor, de Eduar El-Jarrat. El autor intelectual, el líder, el fiel a la doctrina marxista y al materialismo dialéctico. El adorador de las ideas y, al mismo tiempo, quien las critica, el hombre recto, varonil y sincero.

Es el tiempo del autor de los años cuarenta con su grupo de amigos: Antoine Jairalah, Kassem Ishak, Kamel El Sawi, Zeinab y Gamalat. Estamos en la Alejandría de los revolucionarios, con sus cafés escondidos de los agentes de la policía secreta, con sus trenes y metros. Tiempo de las cárceles y los campos de concentración.

Pero, estamos en el tiempo de la redacción de la obra, o sea, con El-Jarrat después de más de cincuenta años, hacia el 2000, en los años en que "el país está sometido al poder de los intermediarios, los estafadores de bancos, los contrabandistas de divisas, el extranjero bajo el pretexto de la privatización y globalización, los sobornados, los traficantes de armas, los falsificadores y los emperadores de la droga [...]

La distancia entre las clases sociales llega al punto de que en una noche uno gasta siete millones y medio de dólares para celebrar una boda, mientras que la renta per cápita del $80 \%$ de los egipcios no sobrepasa a un dólar diario, uno solo» $(\text { p. } 74)^{64}$.

A la luz de lo dicho, vemos que El-Jarrat yuxtapone el presente con el pasado. Su contraposición de tiempos heroicos del pasado y tiempos pragmáticos del presente trae al primer plano de la narrativa la transformación y el cambio, la adaptación posibilista y la pérdida de los ideales.

Destaca esta obra por el uso de la técnica posmoderna, donde se funde el tiempo de la escritura de la novela con el tiempo inventado y desaparece el abismo que separa una fecha de otra y un protagonista con su pasado.

El ritmo narrativo de la novela es lento. El autor lo consigue mediante los diálogos, las descripciones, los monólogos interiores, los recuerdos y los sueños. Hay que afirmar que la presencia de los monólogos interiores aquí, reflejan el sentimiento de confusión y ambigüedad.

El autor presta gran interés a las descripciones. La obra bucea en un relato descriptivo, que se muestra con gran naturalidad y viveza. El narrador repite y vuelve a repetir los sucesos, los debates, los diálogos en diversas formas y con múltiples detalles. Nos describe minuciosamente todo: las calles, los callejones, los metros, los trenes, los muebles, los vestidos, los muros, las escaleras. Nos retrata los personajes, sus facciones, su forma física, color de la piel, o sea, los pormenores. Hasta nos describe las voces y los olores. El- Jarrat nos hace ver, no leer.

En cuanto al espacio, la novela no deja lugar alguno de la Alejandría de los años cuarenta sin describirlo detalladamente. Además de El Cairo, las cárceles, los campos de concentración. 
Todos estos cuadros van pintados por el autor con pinceladas de un lenguaje ceñido y adecuado al servicio de la trama.

Es obvio el interés del autor por un lenguaje caracterizado por el estilo impresionista y las expresiones poéticas filtradas ${ }^{65}$. Es un lenguaje realista dominado por la naturalidad, algo que notamos, por ejemplo, cuando se describa los detenidos haciendo sus necesidades al aire libre.

El lenguaje oscila entre lo vulgar, cuando nos transmite conversaciones callejeras, entre los obreros en las fábricas o en las casas entre las mujeres; y lo culto, cuando el protagonista discute con los responsables o con los encargados de la seguridad.

De lo anteriormente mencionado, podemos destacar técnicas posmodernas tales como:

\subsubsection{La intertextualidad:}

- La primera, que nos presenta está al comienzo de la obra. Es una cita del Antiguo Testamento, Libro de Proverbios 30 (18-20):

\section{"Hay cuatro cosas que ignoro:}

La senda del águila en los cielos,

La senda de la serpiente en la roca,

La senda de la nave en los mares,

La senda del hombre en el seno materno,

tal es también el camino de la mujer adultera, la cual después de haber comido limpiándose la boca dice: yo no he cometido mal alguno".

Esta cita puede ser la clave para el entendimiento de la obra y la senda que ha elegido el autor para colocar su obra.

- Como en su novela anterior Las rocas del cielo (Sojur al samaa), se empeña Eduar en escribir las cartas enteras que mandó o que le han mandado sus familiares.

- También, es costumbre suya, recurrir a referencias de otros textos suyos, por lo que nos encontramos con muchas de estas alusiones, cuando habla, por ejemplo, de la inalcanzable, lejana y magnífica fortaleza de "Kaitbay" nos remite a su cuento "Frente al mar" (p.122) de su colección Altas paredes ${ }^{66}$. De la misma colección hace, el autor, referencia a doña "Dawlat", protagonista de su cuento "Una aventura amorosa".

- El-Jarrat que es un intelectual que ha leído obras literarias universales, de Oriente y de Occidente, recurre, por ello, a la intertextualidad de textos ajenos, por ejemplo, cuando menciona la librería Schwartz en la calle de Safía Zaglul en Alejandría: "Esta librería era un lugar limpio, selecto y bien alumbrado" se recuerda el cuento de Hemingway "Un lugar bien alumbrado"67.

\subsubsection{La digresión:}

El autor recurre a la digresión para volver a formar momentos de la subconciencia, que aparecen de repente, para construir el espacio memorativo. Estas digresiones tienen como fin relacionar los espacios y los sucesos lejanos, igual a como sucede en las pinturas. Un ejemplo muy claro, es cuando habla el narrador de su sueño revolucionario, entonces recurre a espacios divergentes:

"...he visto la muchedumbre rodeando el Palacio del Sultan Fouad en la plaza de Al-Azhar, gritando por la caída de la tiranía y he oído ecos reclamando la República en todo Egipto»" (p.43) ${ }^{68}$.

\subsubsection{El collage:}

El collage, abunda en la obra. Y al igual que Montalbán, El- Jarrat extrae recortes de periódicos y de revistas de la época, artículos y ensayos de escritores famosos, canciones, cartas, versos de poetas nacionales e internacionales, etc. 
«He leído en Al Ahram de ayer, antes de dirigirme a la Facultad, "La catástrofe del valle" estrenado por Garir Garison y Gregori Beck, una película en el cine Metro en El Cairo, el primer cine con aire acondicionado...» (p.98).

"Hemos leído en "Al Ahram" el día siguiente que se ha detenido a un marinero francés en un café de los "Bárbaros»" (p.89).

"En la calle he oído tocar la última canción de Om-Kolzum [...]:

"¿Por qué me languideces y eres toda mi vida?

¿Qué ha pasado en el amor entre tú y yo ¿

Y la posibilidad de tu ausencia es lo imposible" (p.212) ${ }^{69}$.

\subsubsection{El epitexto:}

En el epitexto se encuentra el título de la obra. Este título está inspirado en la cita, anteriormente mencionada, del Antiguo Testamento.

Esta cita refleja, según Fathy Abu Rafiaa, cómo ha terminado la experiencia de El-Jarrat::

"Una experiencia confusa, donde es imposible conocer su límite. Una experiencia que pone al narrador, y sus interminables preguntas, en busca continua del significado de las cosas"70.

Y si la novela empezó con la falta de fe, pues termina con cierta fe, cuando el protagonista está convencido de que el trabajo y la rebelión hacia el cambio son el camino de la liberación del ser humano, y es al mismo tiempo, el camino del águila que no acaba nunca por mucho que nos penetremos en los cielos del conocimiento:

"¿Acaso ha terminado aquí el camino del águila, o a lo mejor se prolonga sin fin? [...] Pero por muy lejos que se aleje el horizonte, le tiendo la mano, cojo su borde hiriente» (p.430) ${ }^{71}$.

Concluyendo, El camino del águila es una novela de los actos políticos, de los conflictos ideológicos en Egipto a finales de los años cuarenta, pero es, al mismo tiempo, una novela filosófica sobre la relación del yo con los otros y con el mundo que le rodea y sobre los sueños de la utopía. La obra abarca este período con pinceladas de un artista y no con las herramientas de un historiador.

De lo que no cabe duda, es que el mayor logro de Eduar El-Jarrat en esta novela es haber aplicado y compaginado, con este tema tan egipcio e histórico, el cultivo de las técnicas narrativas posmodernas.

\section{Conclusión:}

A la luz de este trabajo y a pesar de las divergencias (diversidades) intelectuales, lingüísticas y de espacio entre Manuel Vázquez Montalbán y Eduar El-Jarrat, hemos encontrado puntos de encuentro en las obras de ambos escritores en cuanto al tema, su forma de abordarlo y el uso de técnicas posmodernas:

1.- Las dos novelas son históricas, pues articulan elementos históricos dentro de una trama estructurada como es una investigación realizada por un personaje-narrador. Se basan, además y en primer plano, en pintar el carácter de un activista en una situación política crucial de la historia de cada país. Amén de llevar cada obra un profundo análisis político así como de los personajes y situaciones.

2.- Las dos presentan el característico proceso de construcción de la historia -novelas metaficcionales-y alternan diversas perspectivas y voces en la trama, abriendo un haz de referencias sobre el personaje y los acontecimientos históricos que constituyen el eje del relato.

3.- Las dos están dotadas de una gran carga autoreferencial y a la vez se mueven entre la crónica y la memoria.

4.- Tanto Galíndez como El camino del águila, utilizan una forma característica posmoderna de pensar y narrar el pasado, no nostálgicamente sino confrontando críticamente pasado y presente. 
5.- Tanto Montalbán como El-Jarrat por medio de la metaficción historiográfica, ahondan en la relación entre ficción e historia. Puesto que la metaficción historiográfica hace especial hincapié en la historificación de la narrativa y la narrativación de la historia ${ }^{72}$.

Este proceso se traduce en ambos escritores en la inserción de la memoria individual en la historia y la inserción de la memoria histórica en la narrativa.

6.- En las dos obras se entrelazan dos vidas, una verdadera y otra ficticia, la del narrador y la del propio autor. Así como conviven en ellas personajes reales.

7.- Tanto Montalbán como El-Jarrat escrutan la historia pasada y la vida presente.

8.- Las dos novelas pueden leerse como "reescritura de la historia", pues las dos son novelas crónicas.

9.- Tanto Galíndez como El camino del águila atraen la atención de los tranquilos lectores para que tomen postura hacia los mecanismos sociales.

10.- Los dos autores evocan personajes y sucesos de otras obras suyas dejando al lector preguntándose dónde ha leído este párrafo o este nombre. Además, ambos escritores están habitados por sus personajes.

11.- Los acontecimientos, la cronología y la temporalidad referencial de la historia entran en las novelas a través de la memoria y la meditación emocionada del narrador, de modo que lo histórico/narrativo se disminuye a favor de lo lírico o lo filosófico.

12.- Sus usos de técnicas posmodernas como el collage, la intertextualidad, la digresión, etc.

\section{Notas:}

[1] 1.- Vázquez Montalbán, Manuel. Galíndez. Barcelona: Seix Barral, 1993.

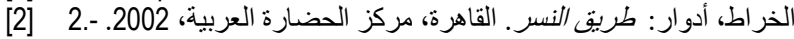

[3] 3.- Prieto, Celia: Historia y novela: poética de novela histórica. Eunsa: Eds., Universidad de Navarra, Pamplona, 1998.

[4] 4.- Ibíd. p. 150.

[5] 5.- Yourcenar, Margarite: Memorias de Adriano (1951). Traducción de Julio Cortázar, Barcelona: Edhasa, 1982.

[6] 6.- Fernández, Santos: Extramuros. Barcelona: Argos Vergara, 1980.

[7] 7.- Fernández, Santos: Cabrera. Barcelona: Plaza y Janés, 1981.

[8] 8.- Galán y Gabriel, José Antonio: El bobo ilustrado. Barcelona: Tusquets, 1986.

[9] 9.- López, José María: La ronda del pecado mortal. Barcelona: Seix Barral, 1992.

[10] 10.- Riera, Carmen: En el último azul. Madrid: Alfaguara, 1996.

[11] 11.- Prieto, Celia, op. cit., p. 150

[12] 12.- Prieto, Celia, «La novela histórica a finales del siglo xx», Madrid: Visor, 1996, p. 214.

[13] 13.- Ibíd. p. 220.

[14] 14.- Ibíd. p. 215.

[15] 15.- Parte central de este ciclo es la utilización de la memoria como material y estrategia narrativa de resistencia frente a la historiografía oficial.

[16] 16.- Esta trilogía empieza con El pianista, Barcelona, Seix Barral, 1985, y termina con Autobiografía del General Franco, Barcelona, Planeta, 1992. En esta trilogía, además, se lleva a cabo una reflexión acerca del papel del intelectual en la sociedad y la postura del escritor frente a la sociedad, materia que preocupa mucho a Montalbán.

[17] 17.- La ética de la resistencia es el nombre que eligió Muriel, la protagonista, para su tesis doctoral.

[18] 18.- Entrevista con Vázquez Montalbán, Quimera 106-107, 1991, p.53.

[19] 19.- Valls, Fernando: La realidad inventada. Barcelona: Crítica, 2003, p. 112.

[20] 20.- Montalbán a sus 17 años, en la Universidad de Barcelona, se enteró por la prensa de EE.UU de la desaparición del Profesor Jesús de Galíndez en Nueva York. Entonces comenzó acumulando textos, fotos, cartas y documentos dice: "Han pasado 30 años y he convivido con Galíndez en la recámara de mi imaginación hasta que, reunidos materiales y seguridades en mi propia escritura, me he decidido a dedicarle una novela en 
la que Jesús de Galíndez se convierte en material de reflexión sobre la ética de la resistencia, escrita precisamente en tiempos en que está en descrédito la ética de la resistencia". Vázquez Montalbán: "Vascos en Santo Domingo», El País, 19/2/1990.

[21] 21.- Vid. al respecto: Presencia vasca en América. Recopilación de trabajos de Jesús de Galíndez publicados en la prensa vasca del exilio. Victoria-Gasteiz: Servicio Central de Publicaciones del Gobierno Vasco, 1984; Iñaki Bernardo Urquijo: Galíndez la tumba abierta. Los vascos y Estados Unidos. Victoria-Gasteiz: Servicio Central de Publicaciones del Gobierno Vasco, 1993; Alberto Elósegui: El verdadero Galíndez. Bilbao: Eds. A. Saldaña Ortega, 1990; y Manuel De Dios Unanué: El caso Galíndez: Los vascos en los servicios de inteligencia de EE.UU, Nueva York, Cupre, 1982.

[22] 22.- Iñaki Bernardo Urquijo, op. cit., aparece en este libro el testamento de Jesús de Galíndez, octubre 1952, Nueva York. Lo curioso es que del cuerpo de Galíndez no se supo nada y sigue su tumba abierta, hasta hoy día.

[23] 23.- Urquijo, Iñaki: op.cit., p.31.

[24] 24.- Ibídem.

[25] 25.- Ibíd., p. 102

[26] 26.- Jesús Galíndez, Revista Quisqueya, junio-julio de 1953, p.45.

[27] 27.- Ibídem.

[28] 28.- Ibíd. p.462.

[29] 29.- Arisa, J.Navarro: « Investigación », El País, 15/4/1990, p.12.

[30] 30.- Pittarello, Elide: «Más sobre historia y ficción: Galíndez, de M.V. Montalbán», en Florencio Sevilla y Carlos Alvar, eds., Actas del XIII Congreso de la Asociación Internacional de Hispanistas. II Siglo XVIII, Siglo XIX, Siglo XX, Castalia, Madrid, 2000, p.743.

[31] 31.- A partir de aquí lo que va entre paréntesis corresponde al número de página de la novela: Galíndez.

[32] 32.- Pittarello, op. cit. p.743.

[33] 33.- Colmeira, op.cit., p.243.

[34] 34.- Bértolo, Constantino: «La verosimilitud literaria», Quimera 69, 1991.

[35] 35.- Bonet, Antonio: La verdad sobre la era de Trujillo, Refutación de "La era de Galíndez". Managua, s.e., 1957. Este libro es un ejercicio estilístico del libro de Galíndez, sin atender a la lógica o al rigor histórico.

[36] 36.- Colmeira, José, op. cit.

[37] 37.- Colmeira, op.cit., p.244.

[38] 38.- «Estructuralmente Galíndez planteaba un problema inicial, lograr dos tiempos históricos diferentes y dos puntos de vista diferenciados. Esto lo resolví hermanando el tono de intimismo y de introspección en el discurso narrativo de Galíndez y de Muriel, utilizando el mismo procedimiento, usando la Segunda persona». Valls, Fernando: entrevista, El Mundo, 15/4/199, p. 23.

[39] 39.- Santiago, Michel: «Galíndez, el no a la dulce ceguera», El Urogallo, 1990, p.74.

[40] 40.- Ibídem.

[41] 41.- Ibid. p. 75.

[42] 42.- Ibid. p. 76.

[43] 43.- M.V.Montalbán: «Vascos en Santo Domingo», El País, 19/2/199, p.13.

[44] 44.- Varios autores: Semiotique narrative et textuelle. Paris, Larousse, 1973. "Le titre affiche la nature du texte et donc le genre de lecture qui lui conviene".

[45] 45.- Colmeira, op.cit., p.243.

[46] 46.- Pittarello, op. cit. p.743.

[47] 47.- Colmeira, op.cit., p.230.

\section{Bibliografía:}

- Asís garrote, Ma Dolores: Última hora de la novela en España. Salamanca: Eudema, 1992, 2. a ed.

- Bértelo Cadenas, Constantino: «Introducción a la narrativa española actual». Revista de Occidente, 98-99, 1989, pp.2960.

- Elósegui, Alberto: El verdadero Galíndez. Bilbao: Eds. A. Saldaña Ortega, 1990.

- Fernández, Santos: Extramuros. Barcelona: Argos Vergara, 1980.

- Gil Casado, Pablo: La novela deshumanizada española (1958-1988). Barcelona: Anthropos, 1990. 
- Hutcheon, Linda: A poetics of Posmodermism: History, Theory, Fiction. New Cork: Routledge, 1988.

- Ledesma Pedraz, Manuela: Escritura autobiográfica y géneros literarios. Jaén: Universidad de Jaén, 1999.

- Martínez Cachero, José María: La novela española entre 1936 y el final de siglo. Madrid: Castalia, 1997.

- -----: «Diez anos de la novela española (1976-1985) por sus pasos contados», Ínsula 464-464 (julio-agosto), 1985, pp.34.

- Prieto, Celia: Historia y novela: poética de novela histórica. Eunsa, Eds. Universidad de Navarra, Pamplona, 1998.

- Rico, Francisco y Daría Villanueva: Historia y citica de la literatura española. Barcelona: Crítica, 1992.

- Rosa Rivero, Alberto Rosa: Memoria colectiva e identidad nacional. Madrid, Biblioteca nueva, 2000.

- Sanz Villanueva, Santos: Historia de la novela social español (1942-1975). Madrid: Alambra, 1980.

- -----: Historia de la literatura española. El siglo XX. Literatura actual. Barcelona: Ariel, 1984.

- Shaw, Donald L.: Nueva narrativa hispanoamericana. Madrid: Cátedra, 1999.

- Soberano, Gonzalo: Novela española de nuestro tiempo. En busca del pueblo perdido. Madrid: El Soto, 1975.

- Unanué, Manuel De Dios: El caso Galíndez: Los vascos en los servicios de inteligencia de EE.UU. Nueva York: Cupre, 1982.

- Urquijo, Iñaki Bernardo: Galíndez la tumba abierta. Los vascos y Estados Unidos. Victoria-Gasteiz: Servicio Central de Publicaciones del Gobierno Vasco, 1993.

- Valls, Fernando: La realidad inventada. Barcelona: Crítica, 2003.

- Vázquez Montalbán, Manuel: Galíndez. Barcelona, Seix Barral, 1993.

- ----: Los mares del Sur. Barcelona: Planeta, 1979.

- -----: Autobiografía del General Franco, Barcelona: Planeta, 1992.

- -----: El Pianista. Barcelona: Mondadori, 1996.

- Villanueva, Darío: Estructura y tiempo reducido en la novela. Barcelona: Anthropos, 1994.

- Yourcenar, Margarite: Memorias de Adriano (1951). Traducción de Julio Cortázar, Barcelona: Edhasa, 1982. 